\title{
Biochemical Characteristics of Mini-implants Sterilised by Different Chemical and Physical Procedures
}

\author{
SILVIA IZABELLA POP'1, DANA CRISTINA BRATU2*, RADU CHIOREAN ${ }^{3}$, RALUCA ADRIANA BALAN², ANAMARIA BUD ${ }^{4}$, \\ HORATIU POMPILIU PETRESCU 5 , CATALIN PETRU SIMON ${ }^{6}$, MIRCEA DUDESCU 3 \\ ${ }^{1}$ University of Medicine and Pharmacy Targu-Mures, Department of Orthodontics, 38 Gh. Marinescu Str., 540139, Targu Mures, \\ Romania \\ ${ }^{2}$ University of Medicine and Pharmacy Victor Babes, Faculty of Dentistry, Department of Orthodontics, 9 Revolution Str., 300070, \\ Timisoara, Romania \\ ${ }^{3}$ Technical University of Cluj-Napoca, Department of Mechanical Engineering, 28 Memorandumului Str., 400114, Cluj Napoca, \\ Romania \\ ${ }^{4}$ University of Medicine and Pharmacy Targu-Mures, Department of Paedodontics, 38 Gh. Marinescu Str., 540139, Targu Mures, \\ Romania \\ ${ }^{5}$ University of Medicine and Pharmacy Victor Babes, Department of Orthopedy and Traumatology, 2 Eftimie Murgu Sq., , \\ 300041, Timisoara, Eomania \\ ${ }^{6}$ University of Medicine and Pharmacy Victor Babes, Department of Anatomy and Embriology, 2 Eftimie Murgu Sq., 300041, \\ Timisoara, Romania
}

\begin{abstract}
One hundred micro-implants from two different manufacturers were used in the study. From each manufacturer (Link from MISTM and Yesanchor from Orlus ${ }^{T M}$ ) the implants were divided in 5 groups: G0 $(n=10)$ new, unused, $G 1(n=10)$ mini-implants inserted in pig bone and removed, ultrasonically cleaned, followed by autoclave sterilization, $\mathrm{G} 2(n=10)$ same insertion protocol of group 2 followed by chemical cleaning with phosphoric gel and autoclave strerilization, $G 3(n=10)$ same insertion protocol of group 1 followed by sandblasting and autoclave sterilization, G4 $(n=10)$ same insertion protocol of group 2 followed by cleaning with distilled water and autoclave sterilization. Maximum insertion torque was recorded and subjected to statistical testing. Our results showed significant differences of the maximum insertion torques between groups of Link mini-implant $(p=0.006)$, and no statistical differences of the maximum insertion torques of the Yesanchor implants $(p=0.33)$. Significant differences $(p<0.001)$ were also recorded between the groups of the two types of minii-mplants when compared. Our findings showed that brand-specific differences in maximum insertion torque exist between the two types of mini-implants.
\end{abstract}

Keywords: micro-implants; sterilizations; maximum insertion torque

Orthodontic mini-implants or TADs (Temporary anchorage devices) are more and more popular in clinical orthodontics. These devices are mainly used to reinforce the anchorage and to facilitate difficult tooth movements. Mini-implants offer numerous advantages: small size, which permits rapid and atraumatic placement in almost all sites within the mouth [1-3].

The reinsertion of a mini-implant might be necessary in some cases, especially when mobility of the mini-screw, due to bone resorption or soft tissue inflammation is observed or when it is used in other part of the mouth for another purpose [4-6].

Treatment costs are significantly increased if new miniimplants are used every time a retrieved one is not reused, in the same patient. On the other side, reusing a medical device can only be performed when its sterilization and preparation does not alter the clinical and mechanical properties of the device [2,4].

The effect of different sterilization protocols on other orthodontic products (pliers, archwires, ligatures etc) was widely studied in the orthodontic literature [7-11, 26-28], but there is less information about the effect of chemical and physical sterilization methods on the surface topography and mechanical properties of the orthodontic mini-screws. Important parametes to test a mini-implant stability and mechanical property are the insertion and the fracture torque $[4,6]$. Especially, the insertion torque is a reliable stability measurement when a mini-implant is desired to be reinserted several times.

Previous studies $[5,7,12$, ] emphasized that only autoclaving sterilization does not affect the fracture torque of the mini-implants. However, microscopic images demonstrated that organic tissue remains are hardly removed from a mini-implants surface, even after many cleanings and sterilization [7].

The objective of this study was to evaluate the insertion torque of mini-implants which underwent different cleaning and sterilization protocols after insertion in pig mandibular bone. It was also aimed to compare the insertion torque of the sterilized implants with the new, unused ones.

\section{Experimental part}

A total number of 100 mini-implants from two different manufacturers (Link from MIS ${ }^{\mathrm{TM}}$, MIS Implants Distribution, Bucharest and Yesanchor from Orlus ${ }^{\mathrm{TM}}$, Seoul, Korea), were included in this study. These two manufacturers were chosen because their mini-implants are the most used and popular in Romania. On the other hand one of the miniimplants type was cylindrical and the other conic, both having the same dimension $1.6 \times 8 \mathrm{~mm}$. From each manufacturer the implants were randomly divided in 5 groups from $\mathrm{G} 0$ to $\mathrm{G} 4$. Group $\mathrm{G} 0(\mathrm{n}=10)$ included new, unused mini-implnats as control group. The G1 group $(n=10)$ consisted of mini-implants inserted in pig

* email: danacristinabratu@yahoo.com; Phone: 0040744835314 
mandibular bone and removed to reproduce the clinical conditions of insertion and removal from jaw bones. The removed mini-implants were subjected to ultrasonical cleaning, at $40 \mathrm{kHz}, 25^{\circ}$ in an ultrasonic washer (Digital Ultrasonic Cleaner, CD 4820, Codyson) completely immersed in detergent, in order to remove the organic debris from their surface. After the 20 min cleaning cycle in detergent solution, the mini-implants were removed, rinsed with distilled water and cleaned ultrasonically once again for 15 minutes in distilled water. This procedure was followed by autoclave sterilization at $121^{0}$, at $15 \mathrm{psi}$ for 20 min (Vakuclav 31B, Melag ${ }^{T M}$, Berlin), according to the recommendations of the manufacturers.

Group G2 ( $n=10)$ underwent to the same insertion and removal protocol of group 2 followed by chemical cleaning. Chemical cleaning consisted of fully coverage with phosphoric ( $\mathrm{H}_{3} \mathrm{PO}_{4}$ ) acid gel, 37\% (Ultra-Etch, Ultradent) and then immersion in $1 \mathrm{~mL}$ of the same acid for $10 \mathrm{~min}$. The samples were irrigated, dried and immersed in $10 \mathrm{~mL}$ sodium hypochlorite $5.25 \%$ ( $\mathrm{NaOCl}$ ) for $30 \mathrm{~min}$. After rinsing with distilled water they were packed in sealed bags and strerilized in autoclave (same protocol as G1).

Group G3 $(n=10)$ underwent to the same insertion protocol of group 1 followed by ultrasonic cleaning in detergent solution for $8 \mathrm{~min}$ and rinsing with distilled water. Then, sandblasting was performed with $\mathrm{Al}_{2} \mathrm{O}_{3}-90 \mu$, at 60 psi, from a distance of $10 \mathrm{~mm}$. The samples were cleaned, once again in ultrasonic bath for $20 \mathrm{~min}$, followed by autoclave sterilization.

Group G4 $(n=10)$ consisted of 10 mini-implants from each manufacturer with the same insertion and removal protocol of group 2 followed by rinsing with distilled water and autoclave sterilization.

In order to test the insertion torque, all the samples from the 5 groups ( $n=100$ ) were inserted in high-density artificial bone. The syntetic bone was custom made for this study (Sawbones Worldwide) to simulate the density and properties of cortical and alveolar cancellous human bone. Each bone block had a simulated cortical bone thickness of $1.5 \mathrm{~mm}(0.48 \mathrm{~g} / \mathrm{cc})$ and a $18.5 \mathrm{~mm}$ thick $(0.16 \mathrm{~g} / \mathrm{cc})$ layer simulating the cancellous bone.

Prior to the experimental investigations of the miniimplants, two small scale tests were conducted in order to determine the rotational speed and the axial load applied during the insertion of the mini-implants. A custom design screw-driver dedicated to this type of medical treatment was consecutively attached to a twist angle transducer and a load cell during a simulated implant insertion by a dental physician that was asked to try to reproduce the actual clinical insertion technique. The first test revealed that it takes betw een 0.8 and 1.1 seconds to perform a 90 degree turn of the screw-driver which corresponds to a roughly $15 \mathrm{rpm}$ (rotations per minute) speed that was

$$
\text { Torque }[\mathrm{Ncm}] \text { vs. Time }[\mathrm{s}]
$$

considered for the future testing of both the reference (new) and the prepared samples of mini-implants. One shortcoming observed during this experiment is that the physician stops to reposition his hand on the screw-driver while the testing machine will run at the constant set speed until the end of test criterion is met. However, this fact only implies that the physician has to overcome the initial static friction at the beginning of each stoke during the actual clinical insertion, but this does notinfluence the maximum torque value that the mini-implants can withstand. For the second test, the physician was asked to push against a load cell while driving a mini-implant in artificial bone. This experiment revealed an axial load of around 50N, so the cart carrying the mandrel that holds the artificial bone was pressed with a $5 \mathrm{~kg}$ weight attached to a pulley system that is fitted on the testing equipment by its manufacturer. Based on the two previously described tests, all the 100 mini-implants belonging to the five groups have been inserted in artificial bone using an Instron 55MT1 Torsion Tester (fig. 1).

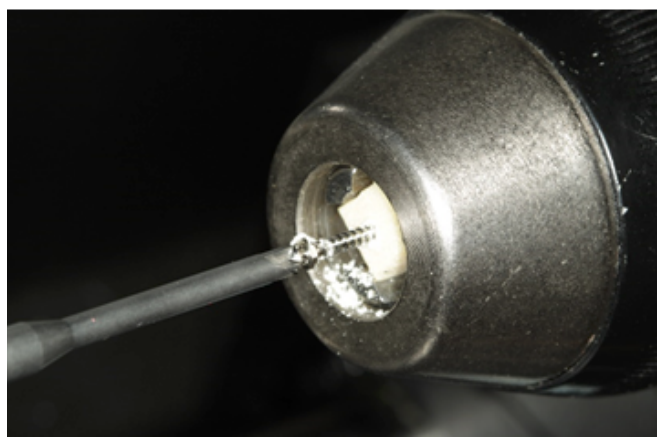

Fig. 1. Maximum insertion torque measurement set-up using the Instron Torsion Tester

The measured data were represented as diagrams ( fig. 2). Both types of implants have a drilling tip followed by a threaded portion, a neck and a screw head. Zone (1) on each curve represents the actual start of the drilling process (marked by the presence of bone chips). This process is slow and steady for the cylindrical mini-implant because only the front edge of the drill cuts into the bone while the torque continues to rise for the conical implant as it also cuts sideways. Zone (2) on the curves corresponds to the moment at which the drilling tip is fully inserted into the bone and the torque will start to rise due to the increase in friction caused by the higher contact surface area as the thread advances. The rate at which the torque increases is again higher in the case of conical implants because of the lateral pressure exerted on the tissue that can sometimes lead to bone cracks in the vicinity of the implant at the upper torque values. Note that the drilling process still continues at the tip of the implant, but the bone density diminishes. Point (3) marks the complete insertion of the implants as the neck's shoulder reaches the surface of the

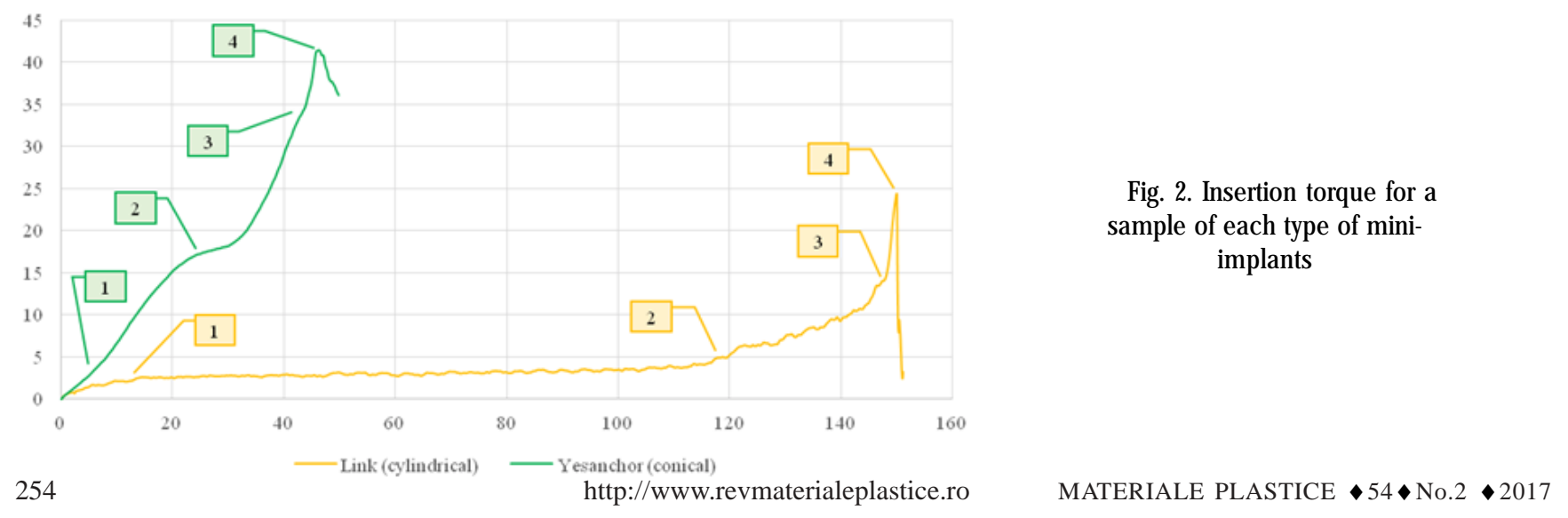




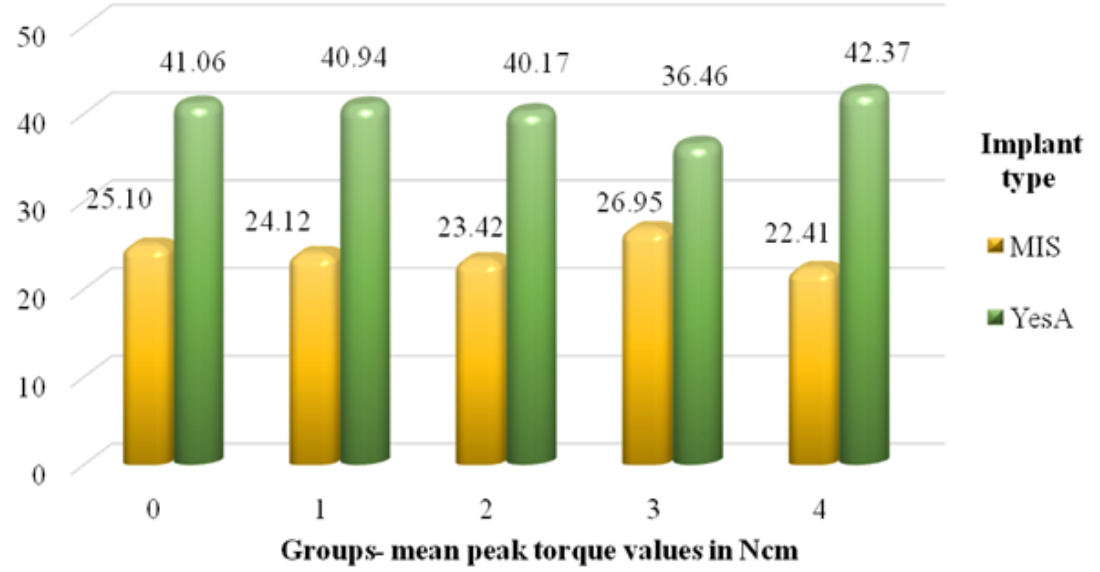

Fig. 3. The average of the maximum insertion torque values for the two types of implants, from group $\mathrm{G} 0$ to $\mathrm{G} 4$

bone. Following this point the torque rises until the implant breaks at point (4). Cases of bone being cleft rather than implant breaking were only observed in the case of conical samples.

Statistical analysis was performed using one-way analysis of variance (ANOVA) and t-test based on the average values of maximum torques for each group. The significance threshold was set to 0.05 .

\section{Results and discussions}

The average of the maximum insertion torque values are summarized for the two types of mini-implants from group $\mathrm{G} 0$ to $\mathrm{G} 4$ in figure 3 .

Average maximum insertion torque values for Link miniimplants varied from $22.40 \mathrm{Ncm}$ to $26.94 \mathrm{Ncm}$ and for Yesanchor implants from $36.46 \mathrm{Ncm}$ to $42.37 \mathrm{Ncm}$.

The student test showed significant difference between group $G 0$ and $G 4(p=0.0177), G 2$ and $G 3(p=0.0402)$ and between $G 3$ and $G 4$ ( $p=0.0135)$ of the Link implants maximum insertion torque values. Group $\mathrm{G} 3$ of the Link mini-implants had a significantly increased insertion torque when compared with groups G2 and G4. No statistically significant maximum torque insertion values were recorded between groups of Yesanchor mini-implants.

One-way ANOVA test show ed significant differences of the maximum insertion torques between groups of Link mini-implant $(p=0.006)$, and no statistical differences of the maximum insertion torques of the Yesanchor implants $(p=0.33)$. Significant differences $(p<0.001)$ were also recorded between the groups of the two types of miniimplants when compared.

Maximum insertion torque is defined as the maximum torque recorded during the insertion procedure of a miniimplant measured in $\mathrm{Ncm}$. It is a result of friction between screw threads and bone (artificial or human) and can be used as a reliable parameter to determine whether primary mini-implant stability can be achieved [1-6]. Although the success rate of the mini-implants might be affected by its maximum insertion torque. In a study made in 2006, Motoyoshi et al.[13] demonstrated that mini-implants stability placed with a maximum insertion torque between 5 and $10 \mathrm{Ncm}$ was higher than maximum insertion torque was below or above these values. In other words, a greater insertion torque does not mean a better stability of the implant. Chaddad et al. [14] found higher values for the ideal maximum insertion torques ( $15 \mathrm{Ncm}$ ). In our study, the recorded maximum insertion torques of the new, unused samples were higher for both the cylindrical Link $(25.10 \mathrm{Ncm})$ and for the conic Yesanchor $(41.02 \mathrm{Ncm}) \mathrm{mini}-$ implantsAlthough, our values were comparable with the

results or rrates da Nova et al.[15] for the same implant diameter (1.6mm). The differences might be explained by variables due to manufacturing process, different manufacturers and shapes of the implants.

Regarding the procedures used for cleaning and sterilization of the implants, we tried to establish which procedure might modify the maximum insertion torque of a screw. The first group G1 underwent sonification in a detergent solution. This procedure should remove the proteinaceous biofilm from the contaminated surfaces, although some studies [16,17] suggested to be insufficient. Analyzing the effect of the sonification to the mechanical properties of a mini-implant, it can be concluded that, in both types (Link and Yesanchor), the maximum insertion torque slightly but not significantly decreased. Estelita et al.[6] compared the fracture torque of the new and ultrasonically cleaned miniimplants fracture torque and revealed no significant differnces. Group G2 underwent chemical cleaning with phosphoric acid. This acid was chosen due to its numerous advantages: low Ph which deletes mineral part of the remaining bone and it is harmless to the implants titanium surface [18]. Sodium hypoclorite is also a useful chemical agent used to dissolve organic parts [11]. Chemical cleaning reduced the maximum insertion torque for both types of implants, but the decrease was not statistically significant. Similarities between our study and Norrollahians et al.[5] study was found. The maximum insertion torque of the chemically cleaned implants was not significantly reduced in both studies.

Sandblasting methods are recommended to treat the surface of titanium implants in order to increase surface area and to provide a better bone-to -implant contact [1924]. It was also suggested that, by mechanical stripping, the surface of a used implant is better cleaned. Regarding its effect on the mechanical properties, it has been suggested $[3,23]$ that the removal torque was increased while, the fracture torque was not modified [6]. We found statistically significant greater insertion torque for the sandblasted Link mini-implants $(26.94 \mathrm{Ncm})$ and lower insertion torque for Yesanchor (36.46 Ncm) implants. Because, all the other variables (particle size, cleaning process after sandblasting etc) were the same for $\mathrm{G} 3$ group of the two types of implants, the implants shape and manufacturer were the only factors that can explain the differences in results.

Ithas been suggested that several autoclave sterilization cycles (up to 50 times) [12] does not affect implants strength and fracture torque. Mattos et al. [4] study also demonstrated that no significantly changes were observed in the resistance to fracture of the autoclaved mini- 
implants. On the other hand, Akyalcin et al. [7] observed differences between maximum insertion torques of four commercially available mini-implants, in cycles of 1, 5 and 10 autoclave sterilization. The maximum insertion torque increased in the case of Vector and KLS Martin miniimplants, which might suggest a positive effect of the sterilization on the mini-implant stability. In our study, we sterilized our mini-implants from group $\mathrm{G} 4$ only once. The effect was a slight decrease of the maximum insertion torque in Link implants while, in the case of Yesanchor implants the measured parameter increased, but not significantly.

\section{Conclusions}

Our findings showed that brand-specific differences in maximum insertion torque exist between the two types of mini-implants.

Different chemical and physical cleaning and sterilization procedures have variable effects on the maximum insertion torque of the mini-implants. Statistical variability was observed between the five groups of Link implants.

Further studies are required to establish modification of other parameters (surface topography, fracture and removal torque) of the studied mini-implants.

Acknowledgment:This work was supported by the University of Medicine and Pharmacy of Tîrgu Mures, Research Grant number 17800/13/22/12/2015.

\section{References}

1.NOOROLLAHIAN S, ALAVI SH, RAFIEI E. The effect of multiple processing and re-use on orthodontic mini-screw torque values. Dent Res J, 9, No 4, 2012, p. 447-451

2.CHO K, BAEK SH. Effects of predrilling depth and implant shape on the mechanical properties of orthodontic mini-implants during the insertion procedure. Angle Orthod., 82, No. 4, 2012, p. 618-624

3.CHEN Y], CHEN YH, LIN LD, YAO CC. Removal torque of miniscrews used for orthodontic anchorage - A preliminary report. Int J Oral Maxillofac Implants, 21, 2006, p. 283-289

4.MATTOS CT, RUELLAS AC, ELIAS CN. Is it possible to re-use miniimplants for orthodontic anchorage. Results of an in vitro study? Mater Res., 13, 2010, p.521-525.

5.NOOROLLAHIAN S, ALAVI SH, MONIRIFARD M. A processing method for orthodontic mini-screws reuse. Dent Res J. 9, 2012, p. 447-451 6.ESTELITA S, GUILHERME J, CHIQUETO K, FERREIRA1 ES. Effect of Recycling Protocol on Mechanical Strength of Used MiniImplantsInternational. Int. J Dent. 2014

7.AKYALCIN S, MCIVER HP, ENGLISH J, ONTIVEROS J, GALLERANO R. Effects of repeated sterilization cycles on primary stability of orthodontic mini-screws. Angle Orthod. 83, No. 4, 2013 p. 674-679 8.WHANG CZ, BISTER D, SHERRIFF M. An in vitro investigation of peak insertion torque values of six commercially available miniimplants. Eur J Orthod.33, 2011, p.660-666

9.KARCH M, ALT E, SCHMITT C, SCHOMIG A. Reimplantation of an infected, abdominally implanted defibrillator in the subpectoral region. J Cardiovasc Surg. 37, 1996, p. 67-70

10.PRINGLE RA, LEMAN RB, KRATZ JM, GILLETTE PC. An argument for pacemaker reuse: Pacemaker mortality in 169 patients over ten years. Pacing Clin Electrophysiol.9, 1986, p.1295-1298
11.SONIS AL. Air abrasion of failed bonded metal brackets: A study of shear bond strength and surface characteristics as determined by scanning electron microscopy. Am J Orthod Dentofacial Orthop. 110, 1996, p.96-98

12.ADELSON RT, DEFATTA RJ , DUCIC Y. Integrity of craniofacial plating systems after multiple sterilization procedures. J Oral Maxillofac Surg. 2007;65:940-944

13.MOTOYOSHI M, HIRABAYASHI M, UEMURA M, SHIMIZU $N$. Recommended placement torque when tightening an orthodontic mini-implant. Clin Oral Implants Res. 17,2006, p.109-114

14.CHADDAD K, FERREIRA AF, GEURS N, REDDY MS. Influence of surface characteristics on survival rates of mini-implants. Angle Orthod.78, 2008, p. 107-113

15.PRATESDA NOVA MF, CARVALHO FR, ELIASCN, ARTESE F. Evaluation of insertion, removal and fracture torques of different orthodontic mini-implants in bovine tibia cortex. Rev. Dent. Press Ortodon. Ortop. Facial. 13, no.5, 2008, p. 76-86

16. PARK JH, OLIVARES-NAVARRETE R, BAIER R. Effect of cleaning and sterilization on titanium implant surface properties and cellular response. Acta Biomaterialia. 8, no. 5, 2012, pp. 1966-1975

17.ELIADES T, ZINELIS S, PAPADOPOULOS MA, ELIADES G. Characterization of retrieved orthodontic miniscrew implants. Am J Orthod Dentofacial Orthop.135, 2009, p.101-107

18. PEREZ S, VILLAESCUZA M. Measurement of ridge alterations following tooth removal: a radiographic study in humans. Clin Oral Implant Research,21,2010, p 237-242

19.CHANG YL, BAEK SH. In vitro and in vivo mechanical stability of orthodontic mini-implants. Angle Orthod, 82, No. 4, 2012, p. 611-617 20.SCHWARTZZ, LOHMANN CH, BLAU G, BLANCHARD CR, SOSKOLNE AW, LIU Y, Re-use of implant coverscrews changes their surface properties but not clinical outcome. Clin Oral Implants Res.11,2000, p. 183-194

21.CRISMANI AG, BERTL MH, CELAR AG, BANTLEON HP, BURSTONE C). Miniscrews in orthodontic treatment: Review and analysis of published clinical trials. Am J Orthod Dentofacial Orthop.137, 2010, p. 108-113

22.MOON CH, LEE DG, LEE HS, IM JS, BAEK SH. Factors associated with the success rate of orthodontic miniscrews placed in the upper and lower posterior buccal region. Angle Orthod.78, 2008.101-106.

23.CHENG SJ, TSENG IY, LEE JJ, KOK SH. A prospective study of the risk factors associated with failure of mini-implants used for orthodontic anchorage. Int J Oral Maxillofac Implants.19, 2004, 100106

24.LIM SA, CHA JY, HWANG CJ. Insertion torque of orthodontic miniscrews according to changes in shape, diameter and length. Angle Orthod.78, 2008, p.234-240

25.WILMES B, DRESCHER D. Impact of insertion depth and predrilling diameter on primary stability of orthodontic mini-implants. Angle Orthod.79, 2009, p. 609-614

26.NEMES M., GRUJIC D., CRAINICEANU Z., JIGA L., PRILIPCEANU G., OLARIU D., BODOG F., BRATU T., Breast reconstruction with autologous tissue - our clinical experience, Chirurgia, Vol. 107, Issue: 2, Pages: 199-205, MAR-APR 2012

27.CRAINICEANU, Z., IANES, E., MATUSZ, P., BLOANCA, V., SELEACU, E., NARAD, V., NARAD, G., NODITI, G., BRATU, T., Innovative Method of Titanium Plate Use for Morphological and Functional Human Face Recontruction, Mat. Plast., 53, no. 3, 2016, p. 518

28.PINZARU, I., TRANDAFIRESCU, C., SZABADAI ,Z., MIOC, M., LEDETI, I., CORICOVAC, D., CIURLEA, S., GHIULAI, R M., CRAINICEANU, Z., SIMU, G., Synthesis And Biological Evaluation Of Some Pentacyclic Lupane Triterpenoid Esters, Rev. Chim. (Bucharest), 65, no. 7, 2014, p. 848

Manuscript received: 21. 12. 2016 